\section{INJURY SURVEILLANCE AT THE NATIONAL HOSPITAL OF SRI LANKA 2009-2012}

${ }^{1}$ Achala Upendra Jayatilleke, 'Megha Ganewatte, ${ }^{2}$ Samindi Samarakoon, ${ }^{2}$ Kapila Wickramanayaka, ${ }^{2}$ Anil Jasinghe. ${ }^{1}$ Postgraduate Institute of Medicine, University of Colombo, Colombo, Sri Lanka; ${ }^{2}$ National Hospital of Sri Lanka, Colombo, Sri Lanka

\subsection{6/injuryprev-2016-042156.955}

Background Injuries are the leading cause of hospitalisation in Sri Lanka. The Accident and Orthopaedic Service (AOS) in the National Hospital of Sri Lanka (NHSL) is the largest trauma care centre in the country. In 2008, an injury surveillance system (ISS) was established at the NHSL. Objective of this study was to present the results of the injury surveillance at NHSL from 2009 to 2012 .

Methods Data were extracted from the ISS database for the period between 2009 and 2012 and were analysed to provide descriptive statistics.

Results In total, 80,718 patient records were available from 2009 to 2012 , with injuries. Of them, $73.0 \%$ were male and $27.0 \%$ were female. Majority of injuries were unintentional (85.2\%). Other types of injuries were injuries due to violence (13.4\%) and self-harm (1.4\%). Of unintentional injuries, transport injuries accounted to $33.1 \%$, and $66.9 \%$ were non-transport injuries. Falls accounted for $62.8 \%$ of all non-transport injuries. Two or three wheeled vehicles crashes, non-collision injuries, heavy vehicle crashes, and car crashes accounted for 28.1\%, 27.0\%, $15.1 \%$, and $12.9 \%$ of transport injuries respectively. Of all the injuries, $37.6 \%$ occurred in sports areas, and $34.4 \%$ happened at homes. Of self-inflicted injuries, 37.2\% were done under the influence of alcohol. Severe injuries were seen in $1.5 \%$ and $80.3 \%$ were moderate in severity. Of all the admissions, $53.3 \%$ stayed in the hospital for less than 24 hours. Majority of injured $(88.7 \%)$ took more than an hour to reach the hospital.

Conclusion Unintentional injuries are common in Sri Lanka. Because non- transport injuries accounted for $67 \%$ of unintentional injuries, and falls were the commonest of them, policies should be introduced make environments safe and prevent such injuries. Because majority of injured were unable to reach a health facility within the golden first hour, reasons for this delay should be investigated and addressed. Interventions should be taken to prevent injuries at sports areas and homes.

\section{Older people safety}

\section{Post Wed 3.4}

\section{INJURY EVENTS IN RESIDENTIAL AREAS - RISK GROUPS AND ETIOLOGICAL FACTORS FOR FALLING, CUTTING AND POISONING}

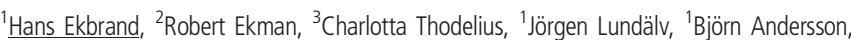
${ }^{3}$ Inga Malmqvist. 'University of Gothenburg, Sweden; ${ }^{2}$ University of Örebro, Sweden; ${ }^{3}$ Chalmers University of Technology, Sweden

10.1136/injuryprev-2016-042156.956

Background Injury events in homes constitute a major social problem. Falling, cutting and poisoning make up 85 per cent of all injury events in residential areas.
This study is based on a unique data set that includes several million cases of falling, cutting and poisoning in Sweden during the period 1990-2013 which lead to either to death, hospitalisation or to a visit to a health care provider, and a control group randomly selected from the population.

Three riskgroups are given special attention in the analysis: (1) old people, (2) children, (3) persons with disabilities and or long term illnesses.

Methods Multilevel regression analysis and geographical information systems, GIS.

Results The results show the probability for each riskgroup to be exposed to each type of injury event, and how this probability varies with place (GIS), previous exposure, type of household, socioeconomic status and type of housing.

Conclusions The project is ongoing. Our cross-sectorial group has demonstrated the importance of injury epidemiology as a guiding principle in architectural design, particularly for high-risk groups.

\section{THE MOBILITY PLANNING TOOL: HELPING OLDER ADULTS PREPARE FOR CHANGES IN MOBILITY}

Gwen Bergen, Bethany West, Susan Dugan, Ann Dellinger, Erin Sauber-Schatz, Grant Baldwin. Centres for Disease Control and Prevention, National Centre for Injury Prevention and Control, USA

\subsection{6/injuryprev-2016-042156.957}

Background As we age our transportation options may become more limited due to mobility changes. These mobility changes may include declining driving abilities, or factors related to ageing and health. The objective of this study was to develop and evaluate a mobility assessment tool for older adults that would help them consider their mobility options as they age.

Methods A four-page Mobility Assessment Tool was developed that was designed to identify current and future mobility needs and challenges. An evaluation questionnaire that measured mobiltiy-related attitudes, beliefs and opinions was administered by phone to 1000 respondents age 60-74 years, who reported good or very good mobility Respondents were asked initial questions, given the tool for review, and then asked follow-up questions. Also, respondents had the opportunity to comment on the usefulness of the tool as they consider alternative mobility options.

Results Mobility-related attitudes increased after reviewing the tool. On a scale of 1-5 (where 1 equals "not at all" and 5 equals "very much"), the average scores increased for thinking about mobility from 2.4 to 3.4 ( $\mathrm{p}<0.0001$ ), for thinking about protecting mobility from 2.5 to 3.8 ( $p<0.0001$ ), and for feeling confident about knowing how to protect mobility from 3.5 to 4.2 ( $\mathrm{p}<0.0001)$. The most frequently reported challenges to mobility were driving and other transportation barriers (48\%) and physical mobility (18\%). Most respondents found the tool understandable (97\%) and easy to complete (94\%) with twothirds finding the tool relevant. Reasons given for not liking the tool included that it wasn't applicable to their situation, or gave no new information.

Conclusions Administering the Mobility Assessment Tool with older adults resulted in increased awareness of the mobility challenges they could face, and helped them be more confident of being able to protect and preserve mobility options as they age. 